\title{
Picosecond Pulse Generation in a Benzene Raman Generator Amplifier System
}

\author{
B. Meier and A. Penzkofer
}

Naturwissenschaftliche Fakultät II-Physik, Universität Regensburg, W-8400 Regensburg, Fed. Rep. Germany

Received 28 January 1991/Accepted 7 June 1991

\begin{abstract}
Picosecond ruby laser pulses generate simultaneously Stokes pulses of the $992 \mathrm{~cm}^{-1}$ ring breathing mode and of the $3063 \mathrm{~cm}^{-1} \mathrm{CH}$-stretching mode of benzene in a Raman generator cell by stimulated Raman scattering under self-focusing conditions. The Raman generator light is spectrally filtered, collimated, and amplified in three Raman amplifier cells pumped by ruby laser pulses. Both first Stokes lines have been selectively amplified to short, low divergence, intense light pulses.
\end{abstract}

PACS: $4265 \mathrm{C}$

The vibrational stimulated Raman scattering process $v_{\mathrm{L}} \rightarrow v_{\mathrm{S} 1}+v_{\mathrm{v}}$, where $v_{\mathrm{L}}$ is the laser frequency, $v_{\mathrm{S} 1}$ is the first Stokes frequency, and $v_{\mathrm{v}}$ is the vibrational excitation frequency, is widely used to generate intense first Stokes Raman pulses [1-7]. Under intense pumping conditions the stimulated Raman scattering depletes the pump laser and the generated Stokes light becomes the pump source of higher order Stokes light generation by the processes $v_{\mathrm{S} n} \rightarrow v_{\mathbf{S} n+1}+v_{\mathrm{v}}$ [1-14]. Four photon mixing processes like $v_{\mathrm{S} 1}+v_{\mathrm{S} 1} \rightarrow v_{\mathrm{L}}+v_{\mathrm{S} 2}$ may contribute to the higher order Stokes light generation if the corresponding phasematching angles are small [15-17]. Parametric Stokes anti-Stokes coupling [1-5], $v_{\mathrm{L}}+v_{\mathrm{L}} \rightarrow v_{\mathrm{S} 1}+v_{\mathrm{AS} 1}$, and higher order anti-Stokes coupling, like $v_{\mathrm{ASn}}+v_{\mathrm{L}} \rightarrow v_{\mathrm{S} 1}$ $+v_{\mathrm{AS} n+1}$, are applied to generate intense short-wavelength light pulses $[1-5,8-10,18-21]$.

Steady-state and quasi steady-state stimulated Raman scattering occurs if the pump laser duration $\Delta t_{\mathrm{L}}$ is long compared to the vibrational dephasing time $T_{2}$ [2-5]. In this case the Raman amplification is

$G=\frac{I_{\mathrm{S}}(l)}{I_{\mathrm{S}}(0)}=\exp \left(g_{\mathrm{s}} I_{\mathrm{L}} l\right)$,

where $g_{\mathrm{S}}$ is the steady-state Raman gain factor, $I_{\mathrm{L}}$ is the pump laser intensity and $l$ is the sample length. The stimulated Raman scattering becomes transient for $\Delta t_{\mathrm{L}} \lesssim T_{2}[2-5,22,23]$. Under extreme transient conditions, $\Delta t_{\mathrm{L}} \ll T_{2}$, the amplification changes over to

$G(t) \approx \exp \left[\left(\frac{8 g_{\mathrm{S}} l}{\int_{-\infty}^{t} I_{\mathrm{L}}\left(t^{\prime}\right) d t^{\prime}}\right)^{1 / 2}\right]$,

where $t$ is the time $[22,24]$.
Steady-state stimulated Raman scattering with broadband pump lasers is considered in [25-31]. The Raman gain was found to be similar high as in the case of monochromatic pumping [Eq. (1), gain determined by total pump laser intensity]. Transient stimulated Raman scattering with broad-band pump lasers is described in $[25,32,33]$. Inclusion of the different group velocities of the pump and Raman light in the dispersive Raman media reduces the gain $[32,33]$.

Stimulated Raman scattering occurs in generator cells (no input of Raman signal, amplification of quantum noise $[1-8,24,26,34,35]$ ), in amplifier cells (amplification of input signal $[1-5,36,37])$ and in oscillator arrangements (feedback of Stokes light $[2,4,5,37,38]$ ).

The Stokes wavefront is preserved in steady-state Raman amplifiers [39-42] since the amplification is given by

$$
\begin{aligned}
\frac{d E_{\mathrm{S}}(r, z)}{d z} & =\frac{g_{\mathrm{S}}}{2} I_{\mathrm{L}}(r, z) E_{\mathrm{S}}(r, z) \\
& =\frac{g_{\mathrm{S}} n_{\mathrm{L}} \varepsilon_{0} c_{0}}{4}\left|E_{\mathrm{L}}(r, z)\right|^{2} E_{\mathrm{S}}(r, z),
\end{aligned}
$$

where $E_{\mathrm{S}}$ and $E_{\mathrm{L}}$ are the electrical field strengths, $n_{\mathrm{L}}$ is the refractive index at the pump laser frequency, $\varepsilon_{0}$ is the permittivity, and $c_{0}$ is the vacuum light velocity. This wavefront preservation has gained importance in the generation of nearly diffraction limited Raman amplified pulses with aberrated pump lasers and multi-beam pump sources (beam clean-up [28, 39-43] and beam combination [44 47] of lasers, mainly excimer lasers). Under transient Raman amplification conditions phase pulling 
effects have been observed (amplified Raman signal takes over the phase relation of the pump laser) [37, 48-50].

In a recent paper we studied the stimulated Raman scattering of benzene in a generator cell [51]. Picosecond pulses of a passively mode-locked ruby laser served as pump source. The stimulated Raman scattering was accompanied by small-scale self-focusing [52, 53]. The $992 \mathrm{~cm}^{-1}$ ring breathing mode (steady-state Raman gain factor $g_{\mathrm{s}}=2.9 \times 10^{-11} \mathrm{~m} / \mathrm{W}$ [51]) and the $3063 \mathrm{~cm}^{-1}$ $\mathrm{CH}$-stretching mode $\left(g_{\mathrm{S}}=0.95 \times 10^{-11} \mathrm{~m} / \mathrm{W}\right.$ [51]) of benzene were stimulated simultaneously. The self-phase modulation [53] and cross-phase modulation [54] changed the quasi steady-state stimulated Raman scattering (dephasing times $T_{2}=5.2 \mathrm{ps}$ for $992 \mathrm{~cm}^{-1}$ line [55] and $1.25 \mathrm{ps}$ for $3063 \mathrm{~cm}^{-1}$ line [56]) towards transient stimulated Raman scattering (shortening of effective interaction time). The moving-focus filament formation $[52,53]$ fed pump light to the Raman scattering process, thereby overcoming the pump pulse depletion and allowing the stimulation of both Raman lines.

In this paper the Raman light generated in a benzene generator cell is amplified in benzene amplifier cells which are pumped by picosecond ruby laser pulses. A spectral filtering of the Raman generator output allows the selective amplification of the first Stokes components of the $992 \mathrm{~cm}^{-1}$ or the $3063 \mathrm{~cm}^{-1}$ line. While the Raman conversion efficiency in the generator cell is already quite high (up to $10 \%$ ) and cannot be enhanced significantly in the amplifier cells, the Raman light brightness is increased strongly in the amplifiers by reduction of beam divergence.

\section{Experimental}

The experimental setup of the Raman generatoramplifier system is shown in Fig. 1. The picosecond pump pulses are generated in a passively mode-locked ruby laser (saturable absorber is 1,1'-diethyl-2,2'-dicarbocyanine iodide) [57]. The laser wavelength is $\lambda_{\mathrm{L}}=694.3 \mathrm{~nm}$. Single pulses are separated from the pulse trains by a Pockels cell shutter, and they are amplified in the ruby laser amplifier I up to energies of $30 \mathrm{~mJ}$. The laser pulse duration is $\Delta t_{\mathrm{L}} \approx 35 \mathrm{ps}$.

The mirror $\mathrm{M}_{1}$ splits off $20 \%$ of the ruby pulse energy for reamplification in the ruby amplifier II to pump the final Raman amplifier stage A3. The mirror M2 separates $30 \%$ of the pulse energy for pumping the Raman generator cell G. $50 \%$ of the remaining pulse energy is separated by mirror $\mathrm{M} 3$ to pump the first Raman amplifier stage A1, and the rest of the pump pulse excites the second Raman amplifier cell A2. All Raman cells are $2 \mathrm{~cm}$ long and are filled with benzene.

The pump light to the generator cell is focussed by lens L1 (focal length $20 \mathrm{~cm}$, distance from Raman cell $27 \mathrm{~cm}$ ) in order to obtain efficient stimulated Raman scattering. The generated Raman light is collimated by lens L 2 and spectrally filtered by bandpass filters F. Either the first Stokes component of the $992 \mathrm{~cm}^{-1}$ line or of the $3063 \mathrm{~cm}^{-1}$ line is transmitted. Selection of higher Stokes components leads to no amplification in the Raman amplifier cells.

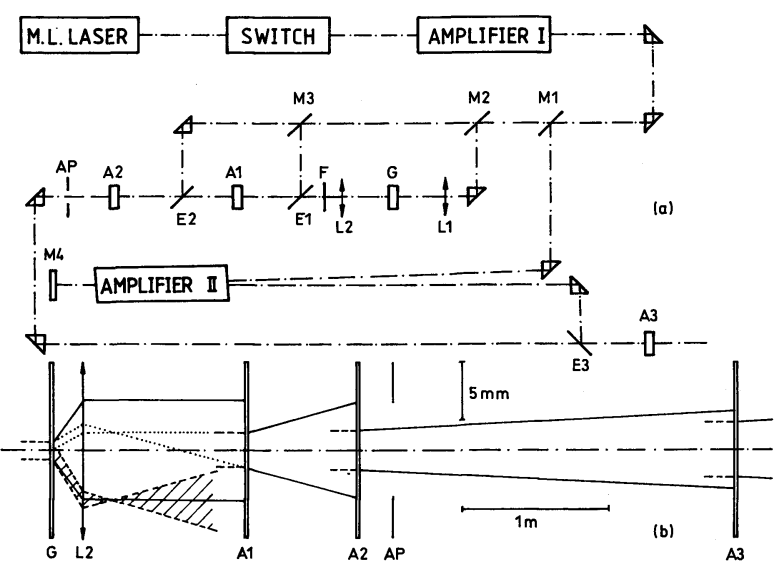

Fig. 1. a Experimental setup. M1-M3, beam splitting mirrors with reflectivities $0.2(\mathrm{M} 1), 0.3(\mathrm{M} 2)$ and $0.5(\mathrm{M} 3)$. L1, L2, lenses (focal length $20 \mathrm{~cm})$. G, generator cell. A1-A3, amplifier cells. F, bandpass filter. E 1-E 3, beam combining edge filters. M4, retroreflecting mirror. AP, aperture with inner diameter of $8 \mathrm{~mm}$. b Illustration of pulse propagation. Dashed lines represent pump beam diameters. Solid lines represent Raman beam diameters. Dotted lines indicate origin of beam divergence behind A1. Hatched region indicates angular spreading behind collimating lens

The Raman amplifier cells are longitudinally pumped. The amplification is limited spatially to the cross-sections of the pump beams. The central Raman pulse energy density is increased and the Raman beam divergence is reduced. The final Raman amplifier A3 is pumped by reamplified ruby pulses.

In Fig. $1 \mathrm{~b}$ the evolution of the beam diameters is illustrated. The halfwidth borders are indicated by solid lines for the Raman light and by the dashed lines for the pump beams. The radial scale is expanded a factor of 80 compared to the axial dimension. The pump beam diameters decrease somewhat with increasing pump pulse energy. The hatched area gives an indication of the low focusibility and low brightness of the collimated Raman beam. The angular spreading depends on the spot size of the Raman light in the generator cell and on the distance between generator cell $G$ and lens L2 (lowest spreading for distance equal to focal length). The dotted lines indicate the origin of the divergence of the Raman light behind the first amplifier A1.

\section{Results}

The generation of Raman light in the generator cell is illustrated in Fig. $2 \mathrm{a}$ and $2 \mathrm{~b}$. The energy conversion efficiency, $\eta_{\mathrm{G}}=W_{\mathrm{S} 1, \mathrm{G}} / W_{\mathrm{L}, \mathrm{G}}$, of pump light into the first Stokes components of the $992 \mathrm{~cm}^{-1}$ and the $3063 \mathrm{~cm}^{-1}$ lines are displayed versus the total pump laser energy $W_{\mathrm{L} 1}$ behind ruby amplifier I. The Stokes energy, $W_{\mathbf{S} 1, \mathrm{G}}$, is measured behind the generator cell. $W_{\mathrm{L}, \mathrm{G}}$ is the pump laser energy before the generator cell. The full divergence angles (measured at the half-peak intensity position) in the saturation region are $\Delta \theta\left(992 \mathrm{~cm}^{-1}\right) \approx 0.02$ and $\Delta \theta\left(3063 \mathrm{~cm}^{-1}\right) \approx 0.05$. The pulse durations were measured to be $\Delta t_{\mathrm{G}}\left(992 \mathrm{~cm}^{-1}\right)=26 \pm 6 \mathrm{ps}$ and $\Delta t_{\mathrm{G}}\left(3063 \mathrm{~cm}^{-1}\right)$ $=20 \pm 6$ ps. The spectral widths were $\Delta \tilde{v}_{\mathrm{G}}\left(992 \mathrm{~cm}^{-1}\right)$ $=5.6 \pm 1.5 \mathrm{~cm}^{-1}$ and $\Delta \tilde{v}_{\mathrm{G}}\left(3063 \mathrm{~cm}^{-1}\right)=17.5 \pm 4 \mathrm{~cm}^{-1}$ 


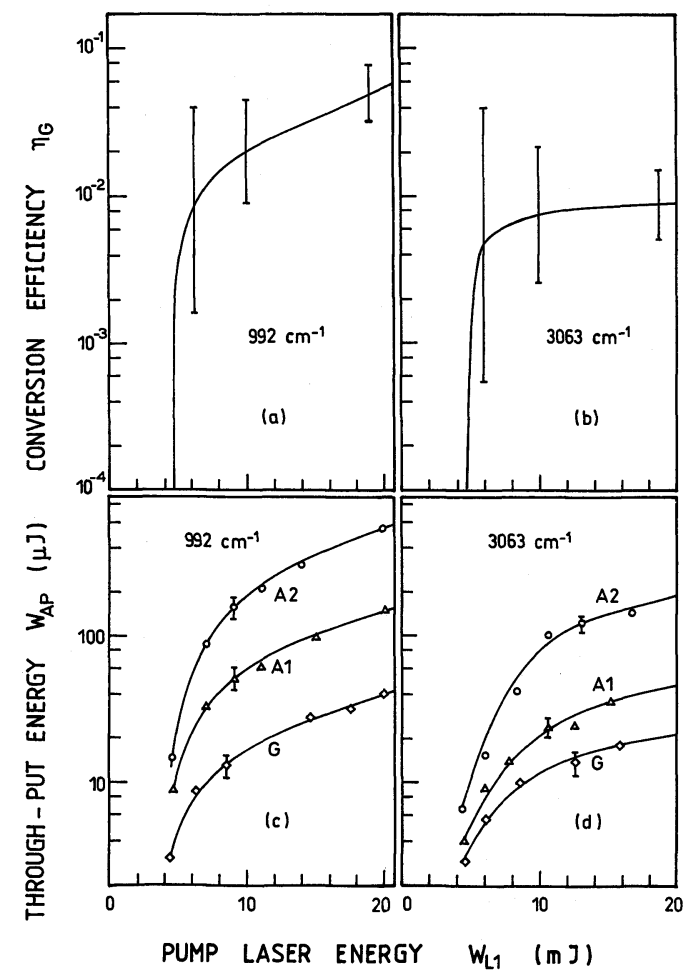

Fig. 2a-d. Stimulated Raman scattering and amplification. $\mathbf{a}$ and $\mathbf{b}$ Energy conversion efficiency of stimulated Raman scattering in generator cell. c and d First Stokes Raman energy through-put through aperture AP

while the spontaneous linewidths are $\Delta \tilde{v}_{\mathrm{sp}}\left(992 \mathrm{~cm}^{-1}\right)$ $=2.04 \mathrm{~cm}^{-1}[55]$ and $\Delta \tilde{v}_{\mathrm{sp}}\left(3063 \mathrm{~cm}^{-1}\right)=8.5 \mathrm{~cm}^{-1}[56]$. The input spectral widths of the ruby pump pulses depended on the pulse switching position $j$. For pulse selection at the pulse train maximum and slightly beyond the pulse train maximum the spectral width was $\Delta \tilde{v}_{\mathrm{L}}(0)=6.2 \pm 1.4 \mathrm{~cm}^{-1}$. Pulse selection 4 pulses in front of the maximum resulted in spectral widths of $\Delta \tilde{v}_{\mathrm{L}}(-4)=2.4 \pm 0.5 \mathrm{~cm}^{-1}$. The spectral width of bandwidth limited Gaussian pulses would be $\Delta \tilde{v}_{\text {bwl }}=0.441 /$ $c_{0} \Delta t_{\mathrm{L}}=0.42 \mathrm{~cm}^{-1}$, where $c_{0}$ is the vacuum light velocity. In most Raman amplification measurements the switching position was around the pulse train maximum $(j=0 \pm 2)$. The spectral broadening of the laser pulses is due to self-phase modulation in ruby. The broadening of the Raman spectra beyond the input pump laser spectral width (for the $3063 \mathrm{~cm}^{-1}$ line) and beyond the spontaneous Raman line width (for the $992 \mathrm{~cm}^{-1}$ and $3063 \mathrm{~cm}^{-1}$ lines) is due to self-phase modulation of the pump pulses and cross-phase modulation of the generated Raman light in the benzene generator cell [54]. The self-phase modulation and cross-phase modulation are enhanced by small-scale self-focusing in the generator cell. The different spectral broadening of pump and Raman light makes the Raman interaction transient $[51,58,59]$. (In [51] the peak intensity necessary to reduce the effective interaction time to 3 ps should read $I_{0 \mathrm{~L}}=7 \times 10^{9} \mathrm{~W} / \mathrm{cm}^{2}$ instead of $7 \times 10^{11} \mathrm{~W} / \mathrm{cm}^{2}$.)

The throughput of Raman light through the aperture $\mathrm{AP}$ (diameter $8 \mathrm{~mm}$ ) is displayed in Fig. 2c and d for the $992 \mathrm{~cm}^{-1}$ and $3063 \mathrm{~cm}^{-1}$ line, respectively. The generator energy and the amplified energies in $\mathrm{A} 1$ and $\mathrm{A} 2$ are shown. The amplification ratios $W_{\mathrm{A} 1} / W_{\mathrm{G}}$ and $W_{\mathrm{A} 2} / W_{\mathrm{A} 1}$ saturate for $W_{\mathrm{L} 1} \gtrsim 8 \mathrm{~mJ}$. The gain saturation was accompanied by the onset of small-scale self-focusing with efficient divergent amplification of spontaneous Raman light. Both first Stokes Raman lines and the second Stokes component of the $992 \mathrm{~cm}^{-1}$ line became observable. The second Stokes component of the $3063 \mathrm{~cm}^{-1}$ line at $1.208 \mu \mathrm{m}$ is out of the range of our detectors. At higher input pump pulse energies $\left(W_{\mathrm{L}}>8 \mathrm{~mJ}\right)$ the pump beam diameter is narrowed due to the stronger pumping of the ruby amplifier $I$. This beam narrowing facilitates self-focusing [52]. The second Stokes light generation is most likely due to the process $v_{\mathrm{S} 1} \rightarrow v_{\mathrm{S} 2}+v_{\mathrm{v}}$. The four-wave mixing process $v_{\mathrm{S} 1}+v_{\mathrm{S} 1}-v_{\mathrm{L}} \rightarrow v_{\mathrm{S} 2}$ is unlikely because the collinear wavevector mismatch $\Delta k=2 k_{\mathrm{S} 1}-k_{\mathrm{L}}-k_{\mathrm{S} 2}=2 \pi\left(2 n_{\mathrm{S} 1} \tilde{\mathrm{S}}_{\mathrm{S} 1}-n_{\mathrm{L}} \tilde{v}_{\mathrm{L}}-n_{\mathrm{S} 2} \tilde{v}_{\mathrm{S} 2}\right)$ is $-40 \mathrm{~cm}^{-1}$ for the $992 \mathrm{~cm}^{-1}$ line and $-312 \mathrm{~cm}^{-1}$ for the $3063 \mathrm{~cm}^{-1}$ line, and the noncollinear phase-matching angles $\varphi=\arccos \left[\left(k_{\mathrm{L}}^{2}+4 k_{\mathrm{S} 1}^{2}-k_{\mathrm{S} 2}^{2}\right) / 4 k_{\mathrm{L}} k_{\mathrm{S} 1}\right]$ of $1.6 \times 10^{-2}$ at $992 \mathrm{~cm}^{-1}$ and $4.1 \times 10^{-2}$ at $3063 \mathrm{~cm}^{-1}$ are larger than the Raman beam divergence angles in the amplifiers. The refractive indices $n_{i}$ involved in the calculations were extracted from data in [60] and are included in Table 1.

Behind the first Raman amplifier A1 beam divergences of $\Delta \theta=(8 \pm 2) \times 10^{-3}$ were measured for both vibrational lines. Behind the second amplifier the divergence reduced to $(1.2 \pm 0.3) \times 10^{-3}$. The Raman pulse durations behind the second amplifier were measured to be $\Delta t_{\mathrm{A} 2}\left(992 \mathrm{~cm}^{-1}\right)$ $=23 \pm 5 \mathrm{ps}$ and $\Delta t_{\mathrm{A} 2}\left(3063 \mathrm{~cm}^{-1}\right)=23 \pm 5 \mathrm{ps}$. The spectral widths were $\Delta \tilde{v}_{\mathrm{A} 2}\left(992 \mathrm{~cm}^{-1}\right)=5.7 \pm 1.7 \mathrm{~cm}^{-1}$ and $\Delta \tilde{v}_{\mathrm{A} 2}\left(3063 \mathrm{~cm}^{-1}\right)=6.3 \pm 1.3 \mathrm{~cm}^{-1}$. The spectral width of the $992 \mathrm{~cm}^{-1}$ line is approximately equal to the spectral width of the pump pulses and of the Raman generator light. For the $3063 \mathrm{~cm}^{-1}$ line the spectra narrowed to a width approximately equal to the pump laser width and slightly smaller than the spontaneous Raman linewidth.

The output Raman energy $W_{\mathrm{A} 3}$ behind the final amplifier A3 is plotted versus the input pump laser energy $W_{\mathrm{L} 2}$ in Fig. 3. The amplification is shown for different input Raman energies $W_{\mathrm{A} 2}$. The highest output energies were $W_{\mathrm{A} 3}\left(992 \mathrm{~cm}^{-1}\right) \approx 6 \mathrm{~mJ}$ and $W_{\mathrm{A3}}\left(3063 \mathrm{~cm}^{-1}\right) \simeq 1.5 \mathrm{~mJ}$ at a pump pulse energy of $W_{\mathrm{L} 2}=40 \mathrm{~mJ}$. The Raman beam divergence behind amplifier A3 remained about the same as the divergence

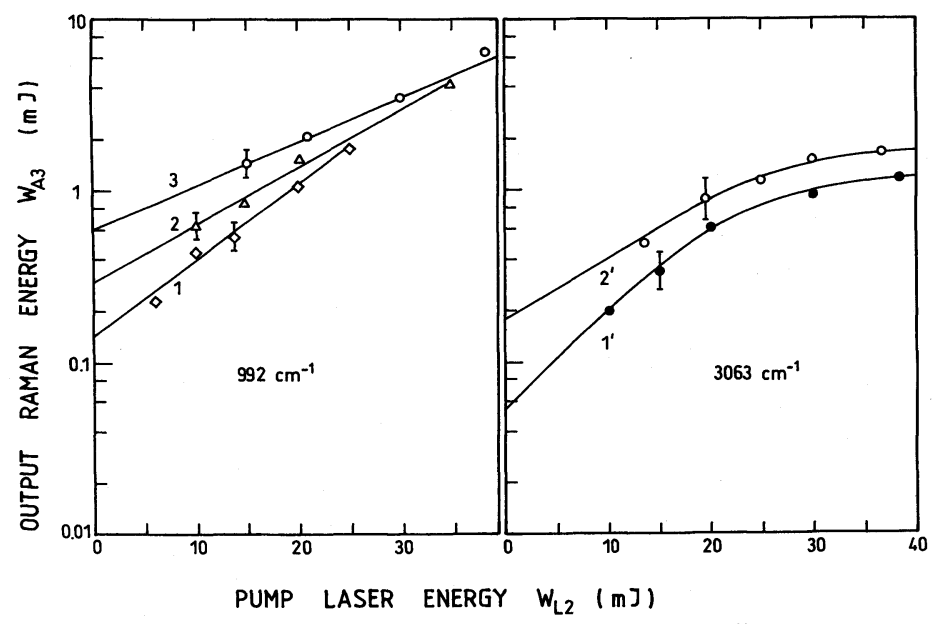

Fig. 3. First Stokes Raman amplification in amplifier cell $A 3$ versus pump pulse energy. The input Raman energies are $10.15 \mathrm{~mJ}$, $20.3 \mathrm{~mJ}, 30.6 \mathrm{~mJ}, l^{\prime} 0.055 \mathrm{~mJ}$, and $2^{\prime} 0.18 \mathrm{~mJ}$ 
behind A2. Values of $\Delta \theta\left(992 \mathrm{~cm}^{-1}\right)=(1.2 \pm 0.2) \times 10^{-3}$ and $\Delta \theta\left(3063 \mathrm{~cm}^{-1}\right)=(1.5 \pm 0.2) \times 10^{-3}$ were measured. The final Raman pulse durations and spectral widths were $\quad \Delta t_{\mathrm{A} 3}\left(992 \mathrm{~cm}^{-1}\right)=30 \pm 7 \mathrm{ps}, \quad \Delta t_{\mathrm{A} 3}\left(3063 \mathrm{~cm}^{-1}\right)$ $=14.5 \pm 5.5 \mathrm{ps}, \quad \Delta \tilde{v}_{\mathrm{A} 3}\left(992 \mathrm{~cm}^{-1}\right)=3.9 \pm 1.4 \mathrm{~cm}^{-1}$, and $\Delta \tilde{v}_{\mathrm{A} 3}\left(3063 \mathrm{~cm}^{-1}\right)=5.5 \pm 1.1 \mathrm{~cm}^{-1}$. In the selective amplification of the $992 \mathrm{~cm}^{-1}$ line no other Raman lines were generated up to the highest pump pulse energy. In the case of the selective amplification of the $3063 \mathrm{~cm}^{-1}$ line some Raman light generation at the $992 \mathrm{~cm}^{-1}$ line was observed occasionally for pump pulse energies above $25 \mathrm{~mJ}$.

Some relevant Raman parameters together with the Raman pulse durations and spectral widths along the Raman generator-amplifier chain are summarized in Table 1. Behind the final Raman amplifier the frequencytime bandwidth product of the Raman signals has become smaller than that of the pump laser indicating some temporal-spectral beam clean-up effect in the Raman amplifiers [37, 48-50].

The dependence of the Raman amplification on the temporal synchronization between pump pulse and input Raman signal is illustrated in Fig. 4 for the first Raman amplifier A1. The energy density amplification $\eta_{\mathrm{A} 1}$ versus delay time $t_{\mathrm{D}}=t_{\mathrm{S}}-t_{\mathrm{L}}$ is shown $\left(t_{\mathrm{L}}\right.$ temporal peak position of pump pulse; $t_{\mathrm{S}}$ temporal peak position of Raman pulse, $t_{\mathrm{D}}>0$ means that the Stokes pulse is behind the pump pulse). The pump laser energy is kept at $W_{\mathrm{L} 1} \approx 10 \mathrm{~mJ}$. The zero delay position $t_{\mathrm{D}}=0$ is set arbitrarily to the peak gain position of the $992 \mathrm{~cm}^{-1}$ line. An exact measurement of the zero delay position was not performed. For the $992 \mathrm{~cm}^{-1}$ line the delay time halfwidth is approximately equal to the pump pulse duration, while for the $3063 \mathrm{~cm}^{-1}$ line the time delay range of efficient amplification is limited to the trailing edge region of the pump pulse. The $3063 \mathrm{~cm}^{-1}$ Raman light which has the smaller steadystate gain factor seems to be generated in the trailing pump pulse region of the generator cell. The small halfwidth of the time delay curve is thought to be due to

Table 1. Performance parameters. The pump laser parameters are $\lambda_{\mathrm{L}}=694.3 \mathrm{~nm}, \Delta t_{\mathrm{L}}=35 \pm 5 \mathrm{ps}, \Delta \tilde{v}_{\mathrm{L}}=5 \pm 2 \mathrm{~cm}^{-1}, \Delta v_{\mathrm{L}} \Delta t_{\mathrm{L}}=5.3 \pm 2.5$, $n_{\mathrm{L}}=1.4948[60], \partial n_{\mathrm{L}} / \partial \lambda \approx-4.6 \times 10^{-5} \mathrm{~nm}^{-1}$

\begin{tabular}{|c|c|c|}
\hline Parameter & $992 \mathrm{~cm}^{-1}$ line & $3063 \mathrm{~cm}^{-1}$ line \\
\hline $\begin{array}{l}\lambda_{\mathrm{s} 1}[\mathrm{~nm}] \\
g_{\mathrm{s}}[\mathrm{m} / \mathrm{W}] \\
T_{2}[\mathrm{ps}] \\
\Delta \tilde{v}_{\mathrm{sp}}\left[\mathrm{cm}^{-1}\right] \\
n_{\mathrm{s} 1} \\
\partial n_{\mathrm{s} 1} / \partial \lambda\left[\mathrm{nm}^{-1}\right]\end{array}$ & $\begin{array}{l}745.7 \\
(2.9 \pm 0.3) \times 10^{-11}[51] \\
5.2[55] \\
2.04[55] \\
1.4926[60] \\
-3.7 \times 10^{-5}\end{array}$ & $\begin{array}{l}881.8 \\
(9.5 \pm 1.5) \times 10^{-12}[51] \\
1.25[56] \\
8.5[56] \\
1.4887[60] \\
-2.2 \times 10^{-5}\end{array}$ \\
\hline $\begin{array}{l}\Delta t_{\mathrm{G}}[\mathrm{ps}] \\
\Delta \tilde{v}_{\mathrm{G}}\left[\mathrm{cm}^{-1}\right] \\
\Delta v_{\mathrm{G}} \Delta t_{\mathrm{G}}\end{array}$ & $\begin{array}{c}26 \pm 6 \\
5.6 \pm 1.5 \\
4.7 \pm 2.5\end{array}$ & $\begin{array}{c}20 \pm 6 \\
17.5 \pm 4 \\
10.5 \pm 5\end{array}$ \\
\hline $\begin{array}{l}\Delta t_{\mathrm{A} 2}[\mathrm{ps}] \\
\Delta \tilde{v}_{\mathrm{A} 2}\left[\mathrm{~cm}^{-1}\right] \\
\Delta v_{\mathrm{A} 2} \Delta t_{\mathrm{A} 2}\end{array}$ & $\begin{array}{l}23 \pm 5 \\
5.7 \pm 1.7 \\
4.2 \pm 2\end{array}$ & $\begin{array}{l}23 \pm 5 \\
6.3 \pm 1.3 \\
4.3 \pm 1.5\end{array}$ \\
\hline $\begin{array}{l}\Delta t_{\mathrm{A} 3}[\mathrm{ps}] \\
\Delta \tilde{v}_{\mathrm{A} 3}\left[\mathrm{~cm}^{-1}\right] \\
\Delta v_{\mathrm{A} 3} \Delta t_{\mathrm{A} 3}\end{array}$ & $\begin{array}{l}30 \pm 7 \\
3.9 \pm 1.4 \\
3.8 \pm 2\end{array}$ & $\begin{array}{l}14.5 \pm 5.5 \\
5.5 \pm 1.1 \\
2.4 \pm 1.3\end{array}$ \\
\hline
\end{tabular}

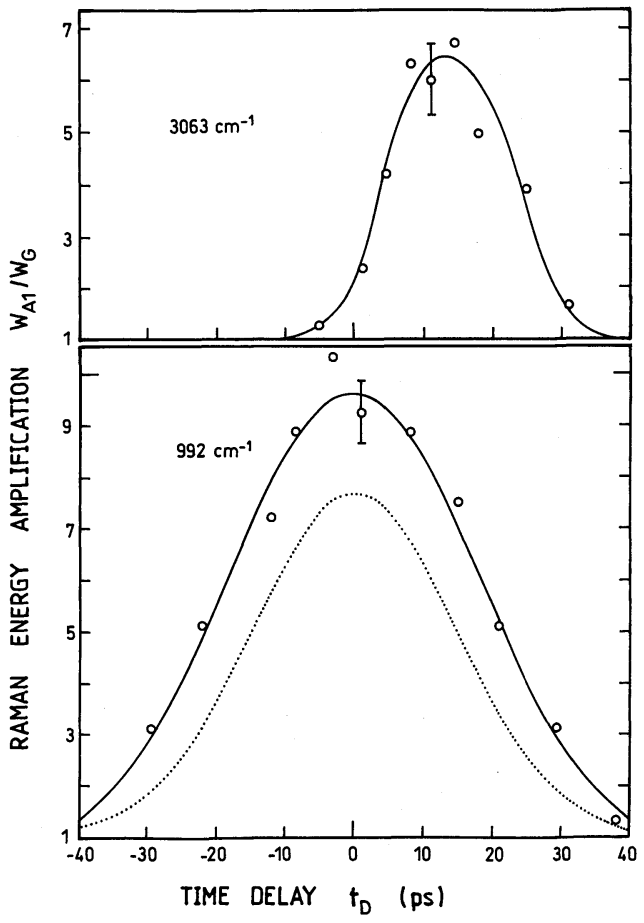

Fig. 4. Dependence of Raman amplification in amplifier cell A1 on temporal delay between Raman generator signal and ruby pump pulse $\left(t_{\mathrm{D}}=t_{\mathrm{S}}-t_{\mathrm{L}}\right)$. Solid curves are fitted to experimental points. Dotted curve shows pulse shape of pump laser

different frequency chirping of the $3063 \mathrm{~cm}^{-1}$ Raman generator light and the pump laser.

The time separation between the pump pulses and the first Stokes pulses in the amplifier cells due to group velocity dispersion is given by

$\delta t_{\mathrm{L}, \mathbf{S} 1}=l\left(\frac{1}{v_{\mathrm{g}, \mathrm{L}}}-\frac{1}{v_{\mathrm{g}, \mathbf{S} 1}}\right)=\frac{l}{c_{0}}\left(n_{\mathrm{g}, \mathrm{L}}-n_{\mathrm{g}, \mathrm{S} 1}\right)$,

where $l$ is the sample length, $v_{\mathrm{g}}$ is the group velocity, $n_{\mathrm{g}}$ the group refractive index, and $c_{0}$ the vacuum light velocity. The group refractive index is determined by [61]

$n_{\mathrm{g}}=\frac{n}{1+\frac{\lambda}{n} \frac{\partial n}{\partial \lambda}}$,

where $n$ is the phase refractive index. The calculations give $\delta t_{\mathrm{L}, \mathrm{s} 1}\left(992 \mathrm{~cm}^{-1}\right)=0.45 \mathrm{ps}$ and $\delta t_{\mathrm{L}, \mathrm{s} 1}\left(3063 \mathrm{~cm}^{-1}\right)$ $=1.25 \mathrm{ps}(l=2 \mathrm{~cm}$ and refractive index data of Table 1$)$. These separations are short compared to the pump pulse duration.

The main effect of the Raman amplifiers is to reduce the beam divergence and to increase the Raman brightness. This behaviour is illustrated in Fig. 5. The solid lines belong to the $992 \mathrm{~cm}^{-1}$ mode and the dashed lines belong to the $3063 \mathrm{~cm}^{-1}$ mode. Part (a) shows the evolution of the Raman beam divergence. The divergence behind lens L2 is set equal to the measured divergence behind amplifier A1 (see hatched region and dotted lines in Fig. 1b). The beam divergence of the pump laser is included (dash-dotted line). The apertured Raman pulse energies (passing aperture AP) are shown in part (b) for the indicated set of pump pulse energies (circles). The 


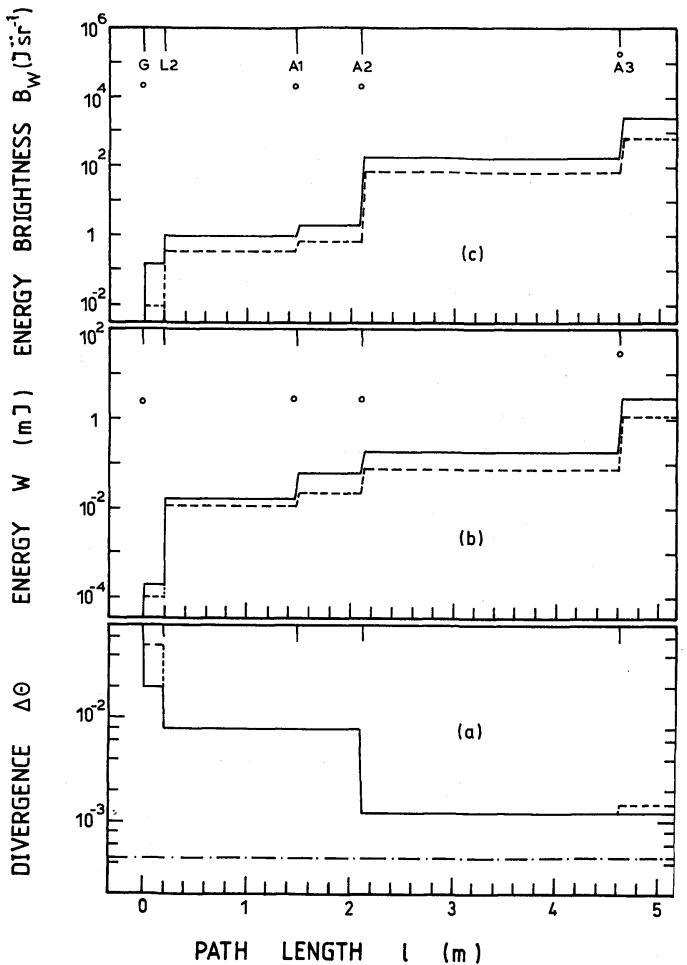

Fig. 5 a-c. Raman light development along propagation direction. a Beam divergence $\Delta \theta$ (FWHM). Solid curve, $992 \mathrm{~cm}^{-1}$ line. Dashed curve $3063 \mathrm{~cm}^{-1}$ line. Dash-dotted line, pump laser. b Apertured first Stokes pulse energies of $992 \mathrm{~cm}^{-1}$ line (solid) and $3063 \mathrm{~cm}^{-1}$ line (dashed). Circles are the pump pulse energies. c Energy brightnesses of the $992 \mathrm{~cm}^{-1}$ line (solid) and the $3063 \mathrm{~cm}^{-1}$ line (dashed). Circles indicate the pump pulse energy brightnesses

energy brightness $B_{W}$ is displayed in part (c). $B_{W}$ is defined by

$B_{W}=\frac{W}{\Delta \Omega}=\frac{4 W}{\pi \Delta \theta^{2}}$,

where $W$ is the pulse energy and $\Delta \Omega$ is the solid angle of divergence. The curves belong to the pump pulse energies of Fig. $5 \mathrm{~b}$. The energy brightness of the collimated Raman beams is increased by approximately a factor of 2500 in the three amplifiers. The energy brightness of the ruby pump pulses are indicated by the circles. Behind the third Raman amplifier the energy brightnesses of the $992 \mathrm{~cm}^{-1}$ and the $3063 \mathrm{~cm}^{-1}$ lines are approximately $1 \%$ and $0.35 \%$ of the energy brightness of the pump laser.

\section{Conclusions}

The generation of intense picosecond Raman pulses in a picosecond ruby laser pumped benzene Raman generator-amplifier system has been studied. The effective stimulated Raman scattering in the generator cell was initiated by small-scale self-focusing and resulted in the simultaneous generation of three Stokes components of the $992 \mathrm{~cm}^{-1}$ breathing mode (highest steady state Raman gain factor $g_{\mathrm{s}}$ ) and of the first Stokes component of the $3063 \mathrm{~cm}^{-1} \mathrm{CH}$-stretching mode (highest $g_{\mathrm{s}} / T_{2}$ value) of benzene. The Raman amplification in the longitudinally pumped amplifier chain allowed the selective stimulation of the first Stokes components of the $992 \mathrm{~cm}^{-1}$ and the $3063 \mathrm{~cm}^{-1}$ lines to high energy brightnesses by increasing the Raman signal energy and reducing the Raman beam divergence. The durations of the Raman pulses remained nearly unchanged in the amplifier cells. The spectral widths of the generated Raman pulses are pulled towards the spectral widths of the pump laser pulses.

Acknowledgement. The authors thank the Deutsche Forschungsgemeinschaft for financial support.

\section{References}

1. N. Bloembergen: Am. J. Phys. 35, 989 (1967)

2. W. Kaiser, M. Maier: In Laser Handbook, Vol. 2, ed. by F.T. Arrecchi, E.O. Schultz-Dubois (North-Holland, Amsterdam 1972) Chap. E2, p. 1077

3. A. Laubereau, W. Kaiser: Rev. Mod. Phys. 50, 3607 (1978)

4. M. Maier: Appl. Phys. 11, 209 (1976)

5. A. Penzkofer, A. Laubereau, W. Kaiser: Prog. Quantum Electron 6, 55 (1979)

6. F.J. Duarte: In Dye Laser Principles with Applications, ed. by F.J. Duarte, L.W. Hillman (Academic, Boston 1990) p. 239

7. D. Klick: In Dye Laser Principles with Applications, ed. by F.J. Duarte, L.W. Hillman (Academic, Boston 1990) p. 345

8. W. Schmidt, W. Appt: Z. Naturforsch. 27a, 1373 (1972)

9. V. Wilke, W. Schmidt: Appl. Phys. 16, 151 (1978)

10. W. Hartig, W. Schmidt: Appl. Phys. 18, 235 (1979)

11. L. Mannik, S.K. Brown: Opt. Commun. 57, 360 (1986)

12. S.R.J. Brueck, H. Kildal: IEEE J. QE-18, 310 (1982)

13. S.F. Fulgham, D.W. Trainor, C. Duzy, H.A. Hyman: IEEE J. QE-20, 218 (1984)

14. T.R. Loree, R.C. Sze, D.L. Barker, P.B. Scott; IEEE J. QE-15, 337 (1979)

15. Y.R. Shen, N. Bloembergen: Phys. Rev. 137, A1787 (1965)

16. V.S. Butylkin, G.V. Venkin, L.L. Kulyuk, D.I. Maleev, Yu.G. Khronopulo, M.F. Shalyaev: Sov. J. Quantum Electron 7, 867 (1977)

17. B. Bobbs, C. Warner: IEEE J. QE-24, 660 (1988)

18. H. Schomburg, H.F. Döbele, B. Rückle: Appl. Phys. B30, 131 (1983)

19. D.J. Brink, D. Proch: Opt. Lett. 7, 494 (1982)

20. N. Morita, L.H. Lin, T. Yajima: Appl. Phys. B31, 63 (1983)

21. S. Szatmári, F.P. Schäfer: J. Opt. Soc. Am. B6, 1877 (1989)

22. R.L. Carman, F. Shimizu, C.S. Wang, N. Bloembergen: Phys. Rev. A2, 60 (1970)

23. C.S. Wang: In Quantum Electronics, Vol. 1, ed. by H. Rabin, C.L. Tang (Academic, New York 1975) p. 447

24. N.J. Everall, J.P. Partanen, J.R.M. Barr, M.J. Shaw: Opt. Commun. 64, 393 (1987)

25. S.A. Akhmanov, Yu.E. D'yakov, L.I. Pavlov: Sov. Phys. JETP 39, 249 (1974)

26. M.G. Raymer, L.A. Westling: J. Opt. Soc. Am. B 2, 1417 (1985)

27. E.A. Stappaerts, W.H. Long, Jr., H. Komie: Opt. Lett. 5, 4 (1990)

28. K.J. Drühl: J. Opt. Soc. Am. B3, 1363 (1986)

29. C. Warner, B. Bobbs: J. Opt. Soc. Am. B3, 1345 (1986)

30. J. Rifkin, M.L. Bernt, D.C. MacPherson, J.L. Carlsten: J. Opt. Soc. Am. B5, 1607 (1988)

31. R.M. Heinrichs, I.C. Winkler: Phys. Rev. A41, 395 (1990)

32. A.Z. Grasyuk, I.G. Zubarev, N.V. Suyazov: Sov. Phys. JETP Lett. 16, 166 (1972)

33. V.R. Blok, G.M. Krochik: Opt. Commun. 80, 89 (1990)

34. N. Fabricius, K. Nattermann, D. von der Linde: In Ultrafast Phenomena IV, ed. by D.H. Auston, K.B. Eisenthal, Springer Ser. Chem. Phys. Vol. 38 (Springer, Berlin, Heidelberg 1984) p. 258

35. R. Frey, F. Pradère: Infrared Physics 16, 117 (1967)

36. D. Ricard, W.H. Lowdermilk, J. Ducuing: Chem. Phys. Lett. 16, 617 (1972) 
37. M.D. Duncan, R. Mahon, L.L. Tankersley, J. Reintjes: J. Opt. Soc. Am. B5, 37 (1988)

38. D.C. Hanna, M.T.T. Pacheco, K.H. Wong: Opt. Commun. 55, 188 (1985)

39. H. Komine, W.H. Long Jr., E.A. Stappaerts, S.J. Brosnan: J. Opt. Soc. Am. B3, 1428 (1986)

40. S.F. Fulghum, D. Klimek, A. Flusberg, D.W. Trainor, C. Duzuy, H. Hyman, J.D. Dangherty, D. Korff: J. Opt. Soc. Am. B3, 1448 (1986)

41. J. Reintjes, R.H. Lehmberg, R.S.F. Chang, M.T. Duignan, G. Calame: J. Opt. Soc. Am. B3, 1408 (1986)

42. A. Mandl, R. Holmes, A. Flusberg, S. Fulghum, D. Angeley: J. Appl. Phys. 66, 4625 (1989)

43. R.S.F. Chang, R.H. Lehmberg, M.T. Duignan, N. Djeu: IEEE J. QE-21, 477 (1985)

44. J. Goldhar, M.W. Taylor, J.R. Murray: IEEE J. QE-20, 772 (1984)

45. S.J. Pfeifer: J. Opt. Soc. Am. B3, 1368 (1986)

46. M.J. Shaw, J.P. Partanen, Y. Owadano, I.N. Ross, E. Hodgson, C.B. Edwards, F.O'Neill: J. Opt. Soc. Am. B3, 1466 (1986)

47. D. Korff, E. Mazur, C. Duzy, A. Flusberg: J. Opt. Soc. Am. B3, 1333 (1986)

48. J.R. Ackerhalt, N.A. Kurnit: J. Opt. Soc. B3, 1352 (1986)
49. G.G. Lombardi, H. Injeyan: J. Opt. Soc. Am. B3, 1461 (1986)

50. M.D. Duncan, R. Mahon, L.L. Tankersley, G. Hilfer, J. Reintjes: J. Opt. Soc. Am. B 7, 202 (1990)

51. B. Meier, P. Weidner, A. Penzkofer: Appl. Phys. B 51, 404 (1990)

52. Y.R. Shen: The Principles of Nonlinear Optics (Wiley, New York 1984)

53. Y.R. Shen, G.Z. Yang: In The Supercontinuum Laser Source, ed. by R.R. Alfano (Springer, New York 1989) p. $1 \mathrm{ff}$.

54. P.L. Baldeck, P.P. Ho, R.R. Alfano: In The Supercontinuum Laser Source, ed. by R.R. Alfano (Springer, New York 1989) p. $117 \mathrm{ff}$.

55. D. Samios, T. Dorfmüller: Chem. Phys. Lett. 117, 165 (1985)

56. W. Seifert, K.L. Oehme, G. Rudakoff, W. Hölzer, W. Carius, O. Schröter: Chem. Phys. Lett. 105, 645 (1984)

57. P. Sperber, A. Penzkofer: Opt. Commun. 54, 160 (1985)

58. N. Bloembergen, M.J. Colles, J. Reintjes, C.S. Wang: Ind. J. Pure Appl. Phys. 9, 874 (1974)

59. P.A. Cornelius, C.B. Harris: Opt. Lett. 6, 129 (1981)

60. Landolt-Börnstein, II. Band, 8. Teil, Optische Konstanten, ed. by K.H. Hellwege, A.M. Hellwege (Springer, Berlin, Heidelberg 1962) pp. 5-632

61. E. Hecht, A. Zajac: Optics (Addison-Wesley, Reading, MA 1974) p. 205 